\title{
Study on Ecologicalization of Electronic Information Industry
}

\author{
Amei Zhang \\ Xi’an International University, 710077, China
}

Keywords: electronic information industry; ecologicalization; ecological mode; exploration; sustainable development

\begin{abstract}
Ecologicalization of electronic information industry is a new model, and it represents the level of modernization of a country and region. This paper describes the specific connotation of electronic information industry. The research status and domestic research situation of electronic information industry in China are analyzed in detail. At present, the basic problem of electronic information industry is the environmental pollution. At the same time, with the development of the economy, and environmental protection ignored, these questions put forward the ecological model of electronic information industry, aim to green development, and promote social, economic and environmental comprehensive coordinated and sustainable development. This paper takes the electronic information industry in Zhejiang Province as an example of ecological aspects for discussion.
\end{abstract}

\section{Introduction}

Electronic information industry is one of the emerging industry model, it is effectively combined with the development of science and technology, we can say that electronic information industrialization process directly represent the development level of a country area, and that it is an important symbol of modern regional economic development. Because the electronic information industry about the holistic material consumption and energy consumption is less, while it creates great economic benefits, the overall product additional value of energy efficiency is spectacular. The advantages of this series of electronic information industry make it be highly chased, and its responses in the overall market are good, the speed of development is also very striking. But it also arise the corresponding problems. Electronic information products in the process of manufacture can produce large quantities of electronic waste and pollution of some chemicals and some electromagnetic pollution, a series of pollution has a great influence on people's lives, the pollution caused by electronic information industry has attracted wide attention both at home and abroad, and it is necessary to transform the traditional electronic information industry into ecological pattern, and it is supported by most countries.

\section{The Connotation of Ecologicalization of Electronic Information Industry}

Electronic information industry ecologicalization emphasizes on the industrialization of electronic information as well as paying attention to ecology, applying ecological economics and sustainable development economics principle, using the ecological, economic laws and the overall construction project for the improvement of the system and the management of electronic information industry, in order to achieve social economic benefit maximization, and use resources to the greatest extent, to the ecological environment of the impact of the minimum, it will be formed by the electronic information industry development to maximum recycling use of waste, to achieve sustainable development of a series of ecological comprehensive target.

Electronic information industry ecologicalization is essential to apply the law of ecological economics and circular economy, and combine to a series of modern science and technology which makes for the sustainable economic development, ecological environment and economy coordinated development. Promoting the whole western Yunnan information industry of material flow, information flow, energy flow and value flow, making sure the system is scientific, reasonable, 
coordinated and sustainable development. In general it is as far as possible to ensure the whole production of clean, green design, ecological management throughout the supply chain production, maximize the use of energy resources industry efficiency, minimize industrial energy consumption, and lower the overall level of industrial pollution at the same time.

\section{Research Status of Electronic Information Industry Ecologicalization at Home and abroad}

Like economic development level, the foreign electronic information industry ecologicalization started earlier in some more developed countries, with the continuous development of electronic information industry, now a lot of developed countries in this area have ecological quite perfect market mechanism, The means mainly used in electronic information industry ecology will practical optimization and adjustment of industrial structure in these countries, the development of environment for scientific and reasonable design, to adopt green technology development, the maximum guarantee the reasonable use of resources, controlling environmental pollution and so on a series of effective measures, the most important thing is that these series of measures to the realization of many enterprises is done consciously abide by consciously, rather than be enforced, such effect is definitely the best, because it is a kind of consciousness.

The development of electronic information industry ecologicalization in some European and American developed country has already formed the great system of the industrial structure, the developed countries through the whole of the industrial structure adjustment, the product structure for the optimization of science, has now formed by electronic information products cutting-edge core technology development and low pollution, high value-added software industry industrial structure, we can say the world is the core of the electronic information industry cutting-edge technology research and development of all focused on the European and American economy more developed countries and regions. In developed countries, many large companies and enterprises attach great importance to scientific and rational design to the environment, such as the HP company as we all know, in their own relevant product design when considering above all is how to ensure that energy consumption is reduced, making the utilization rate of the energy highest use of the structure upgrade is simple, easy to recycle, maximum limit to extend product life cycle, to ensure product minimum use of chemical synthesis of polymer materials, in addition, the enterprise also maximum will be products to the actual use of integrating function, and also is a kind of product integrating a variety of functions, so that it can reduce energy consumption.

The overall development level of developed country is higher, developed country have a great advantage in capital and technology, so they have a great advantage in the electronic information industry ecologicalization too. because of the domestic economic strength and development level is no match for Europe or the United States or other developed countries, so the ecological aspects of electronic information industry has been growing more slowly, at present, China's electronic information industry in ecological aspects mainly adopts measures is to focus on enterprise economic structure form of the structure of product standardization, will update related equipment and so on some aspects of industrial technology, and also has obtained the remarkable result, but there is still gap compared with developed countries as far as its overall level of development, and the electronic information industry production process of electronic garbage in our country does not have specific laws and regulations, It is obviously weak supervision in this respect. Therefore, large foreign enterprises to the extent of e-waste recycling did not included China; the situation is very serious and urgent.

\section{The Pattern of Electronic Information Industry Ecologicalization in Zhejiang Province}

Electronic information industry can be said to be the further development of the economy in Zhejiang province and the guarantee of steady growth, according to a study in the electronic information products manufacturing industry in Zhejiang province in 2001, the main economic indicators maintained a leading domestic level, and sales income presents a increasing trend year by year, what is more, there are a lot of enterprises of electronic information industry is the national 
hundredstrong enterprises, in the electronic information industry technology and equipment configuration of the equipment is also in the leading level of the country, exports of electronic products reached more than 90 billion yuan, the main products of export is communication equipment, TV, computer monitors, audio products, automation of office equipment, electronic components and electronic parts, etc. Electronic information industry in Zhejiang province is very dense, and related professional electronic information industry has its own industrial park, in the entire industrial park, software development is dominant, we can say that software development is one of the leading electronic information industries in Jiangsu region.

We will analyze the pollution emissions and the control situation of electronic information industry in Zhejiang through related data investigation. through the analysis we know that in , the pollution situation of the production of electronic information industry is more serious than the paper industry, textile industry and a series of common industrial pollution, However, electronic information industrial pollution did not attract people's attention and concern, the main reason is that people misunderstand the electronic information industry, people thought it is a high-tech industry, and ignored its pollution situation, on the other hand, the government of Zhejiang province offer great strength to the electronic information industry, leading to the pollution being ignored in the process of production, and electronic information industry has developed rapidly, it brought very big and very considerable economic benefits. So that the advantages of it has covered the pollution it brings. So the electronic information industry in the very great degree restricted the long-term economic development and environmental sustainable development in Zhejiang province.

The environmental pollution problem of Zhejiang electronic information industry is very serious, The daily electronic products we often use such as televisions, air conditioners, washing machines and computers, Once these electronic products are broken they become wastes and it is difficult to deal with, because our country do not have perfect measures to the processing of electronic waste, and the growth of electronic waste is staggering, so it is the top priority of the current electronic information industrialization production to solve the electronic waste to promote economic sustainable development.

The first half of this paper has particularly analyzed the electronic information industry ecologicalization, and then, we will combine the actual situation of Zhejiang and the connotation of the electronic information industry ecology to discuss it. The zhejiang province must fully realize the necessity of the electronic information industry ecologicalization, optimizing the structure of electronic information industry, promoting the development of economy and environment, guaranteeing scientific and ecological development of the electronic information industry to the utmost.

First, we need to scientifically adjust the structure of the electronic information industry products. Second, we should innovative production technology, for example, developing the software industry, raising the level of electronic information industry of the nonphysical, minimizing energy consumption in production. Exhausting gas and waste water emissions of waste residue. Meanwhile, we can also preferentially develop IC design industry, accelerating the development of autonomous design, improving the level of processing and production capacity of the chip. In addition, making full use of the economic benefits of multinational companies, Strengthening maximum limit to transfer the production research and development into China, and constantly attracting foreign investments in order to improve the overall level of electronic information industry, at the same time of strengthening independent innovation, actively cooperating with multinational corporations, making every efforts to have greater breakthroughs in technology, promoting the electronic information industrialization of better and faster development.

Second, we should optimize the layout of the electronic information industry and integrate the overall scale. Making full use of the advantage of the electronic information industry of construction enterprises in the province to build up the ecological culture. Through establishing and perfecting the enterprise service system, we can minimize energy consumption industry resources, thus reducing the production of waste. It is suggested that recycling waste for reuse and obligations be explicitly stipulated in the enterprise, establishing and improving the system of enterprise's social 
and environmental responsibility, insisting on the green production, Not only the corporate leaders but also the staffs should have the profound understanding.

\section{Conclusion}

To sum up, this paper elaborates on the connotation of electronic information industry ecologicalization and the present situation at home and abroad ,it also points out that ecological technology in the electronic information industry of our country has some inadequacies, it have to attract the attention of the country and business leaders, establishing and improving the relevant system, guaranteeing the healthy development of the electronic information industry, promoting the coordinated development of economy and environment better and faster.

\section{References}

[1] Donge Li, Electronic information industry ecology pattern research [J]. Journal of Hengyang normal university, 2004

[2] Zengwei Yuan, Electronic information industry ecology study and its application [J]. Industrial observations, 2004

[3] Wuwei Li, China's development of industrial ecology [J]. Journal of greenery, 2004 [4] Zengwei Yuan, The latest research progress and development trend of future industry ecology [J]. Acta ecological Sonica, 2007 